\title{
HETEROTOPIC PANCREAS PRESENTING WITH UPPER GIT BLEEDING
}

\author{
HAKIM HAN $^{1}$, ALI M ${ }^{2}, \mathrm{KHAN} \mathrm{AS}^{3}$, ALAM KZ ${ }^{4}$, RABBI H ${ }^{5}$, ISLAM MA ${ }^{6}$
}

\begin{abstract}
Heterotopic pancreas or pancreatic rest, refers to extra-pancreatic tissue without an obvious vascular or anatomic connection with the pancreas. Although the frequency of heterotopic pancreatic tissue in autopsy series has been reported as high as $14 \%$, clinical manifestations are rare ${ }^{1}$. Although common in the upper gastrointestinal tract, heterotopic pancreatic tissue rarely causes gastrointestinal bleeding. In a large case series following patients with heterotopic pancreatic tissue, only 7 of 212 patients had any evidence of bleeding ${ }^{3}$. We present a patient who presented with melaena found to have a heterotopic pancreas in the duodenum.
\end{abstract}

Key words: Pancreas, gastrointestinal bleeding, mass in the duodenum.

J Dhaka Med Coll. 2012; 21(1) : 120-123.

\section{Introduction}

Heterotopic pancreas is the presence of normal pancreatic tissue in an anatomically aberrant location lacking vascular, neuronal and anatomic continuity with the pancreas proper. It is not uncommon with an incidence of approximately $0.5-13.7 \%$ in autopsy studies and $0.5 \%$ in upper abdominal laparotomies ${ }^{1,2}$. The lesion occurs in all age groups and is two to five times more prevalent in men than in women ${ }^{3,4}$. The first case of heterotopic pancreas was reported by Schultz in 1729 , but the first histologic confirmation was described by Klob in 1859. Here we report a case of heterotopic pancreas in the duodenum presenting with gastrointestinal bleeding.

\section{Case Report}

A 20 years old male patient got admitted in the hospital with the complaints of melaena for 7 days. He gave no history of peptic ulcer disease or taking NSAIDS. He gave no history of anorexia or weight loss. On physical examination he was moderately anaemic with mild tenderness in the upper abdomen. Investigations revealed heamoglobin $8.6 \mathrm{gm} /$ $\mathrm{dl}$, other biochemical repots were within normal limit. Two units of blood were transfused. Endoscopy of upper GIT revealed an ulcer in the first part of the duodenum with protruding blood vessels which was actively bleeding. Haemostasis was done with injection of adrenalin. Patient developed rebleeding within few hours. So decision for laparotomy was made. Proper counseling was done. Abdomen was opened with upper midline incision. A soft and vascular tumour like lesion was found on the serosal surface of the first part of the duodenum. The duodenum was kocherised and doudenotomy was done. Mucosal aspect of the lesion was bleeding. The lesion with a rim of surrounding duodenal wall was excised. Duodenal wall was repaired. Posterior gastrojejunostomy was made as a protective measure for duodenal repair. A drain was kept in hepatorenal pouch. Abdomen was closed. His postoperative period was uneventful and was discharged on $10^{\text {th }}$ post operative day. On follow up visit after four weeks the patient was found completely well.

Histopathological report was found as wall of duodenum on sections, where the mucosa and the submucosa were unremarkable. Deep to the submucous coat a nodular lesion containing pancreatic tissue was seen. It consisted of exocrine acini present in a lobular pattern along with islet tissue and ducts.

1. Dr. Hafiz Ahmed Nazmul Hakim, Resident Surgeon (Casualty), Dhaka Medical College Hospital, Dhaka.

2. Prof. Mohammad Ali, Department of Hepatobiliarypancreatic Surgery, BIRDEM Hospital, Dhaka.

3. Dr. Arif Salam Khan, Resident Surgeon (General), Dhaka Medical College Hospital, Dhaka.

4. Dr. Kazi Zana Alam, Resident Surgeon (General), Sylhet MAG Osmani Medical College Hospital, Sylhet.

5. Dr. Hashim Rabbi, Assistant Professor, Department of Hepatobiliarypancreatic Surgery, BIRDEM Hospital, Dhaka.

6. Dr. Md. Aminul Islam, Medical Officer, Narsinghdi Sadar Hospital

Correspondence: Dr. Hafiz Ahmed Nazmul Hakim, Resident Surgeon (Casualty), Dhaka Medical College Hospital, Dhaka. Cell phone: +8801712598407, Email: nazmulhakim@yahoo.com 


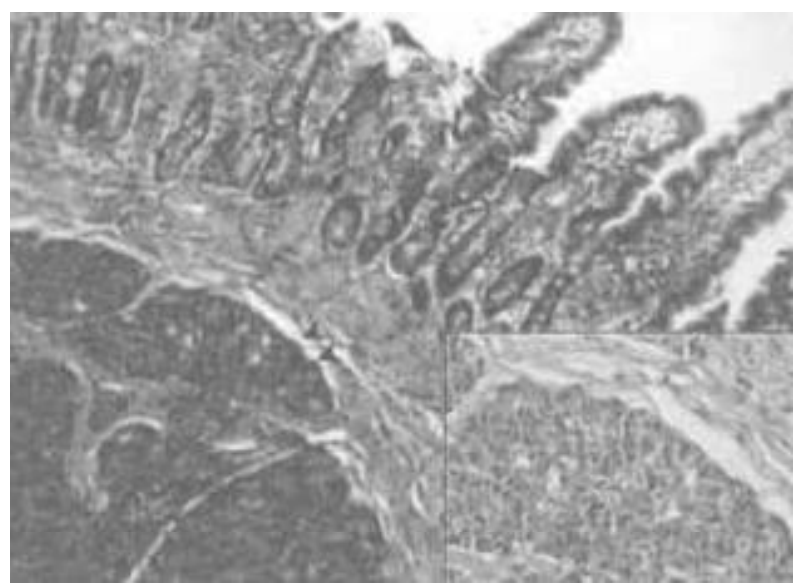

(A)

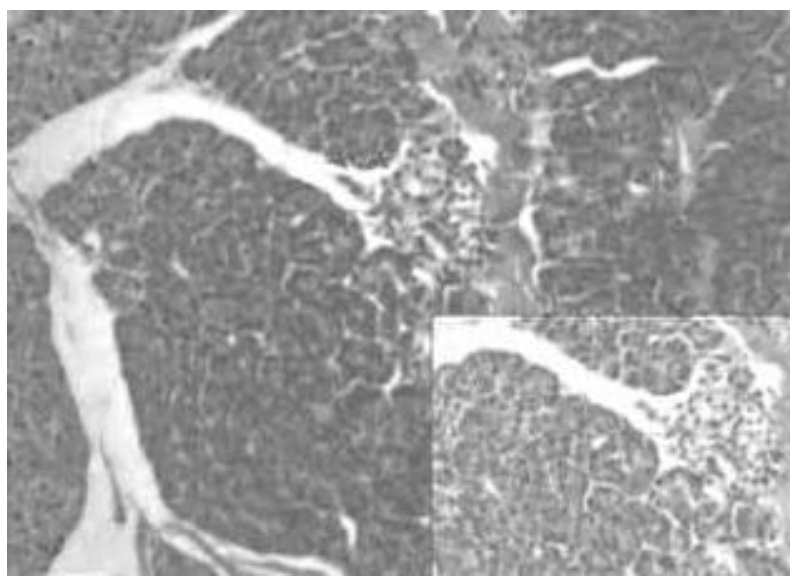

(B)

Fig. 1: Histological examination of surgical specimen. A: submucosal heterotopic pancreas of the duodenum with acinar cells, duct cells, and islets of Langerhans (arrows show acinar cells); B: marked islets of Langerhans between the mucosal and muscular layers of the duodenum (arrow shows islets of Langerhans).
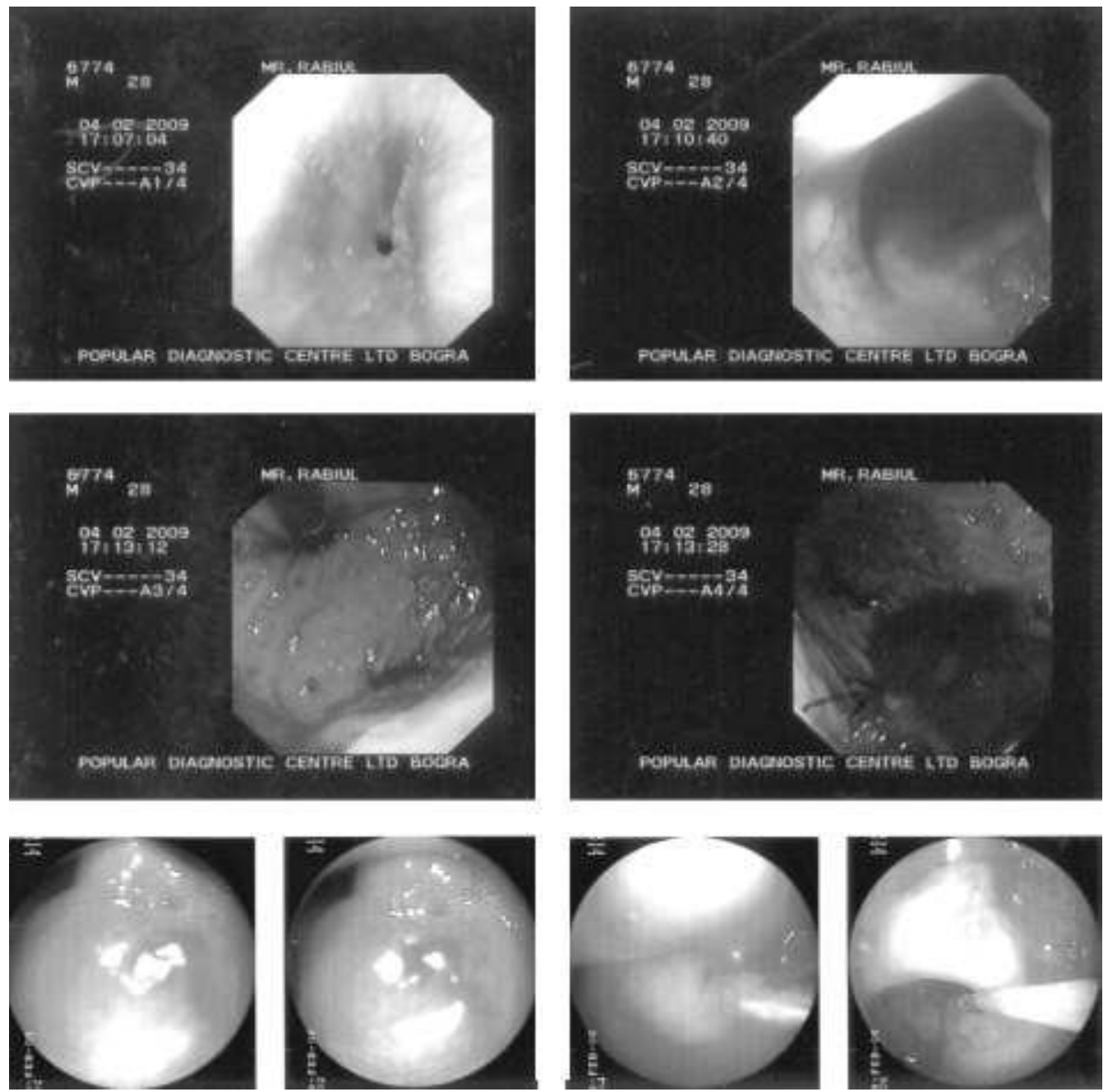

Fig. 2: Endoscopy of upper GIT showing bleeding from duodenal mucosa, as well as haemostasis while inj. adrenalin is administered. 


\section{Discussion}

The pancreas is derived from several endodermal invaginations of the primitive duodenal wall. The dorsal diverticulum becomes the body and tail and the ventral portion becomes the head of the pancreas. The pathogenesis of the heterotopic pancreas is unknown; they are thought to arise during rotation of the foregut when fragments of the pancreas become separated and develop from pancreatic metaplasia of endodermal tissue which migrates to the submucosa during embryonic life ${ }^{2,5}$. In the gastrointestinal tract, pancreatic heterotopia forms round or lobulated white or yellowish lumps of tissue ranging from a few millimeters up to a few centimeters; larger tumors tend to have central umbilication which represents the site of the draining duct. The mass lies most commonly in the submucosa but can present as a subserosal nodule ${ }^{5,6}$. The heterotopic (ectopic) pancreas may contain any mixture of tissues normally found in the pancreas. Heinrich classified the heterotopic pancreas into 3 types: type I, all the components of the pancreas including ducts, acini, and endocrine islets; type II, ducts with acini; and type III, ducts with a few acini or dilated ducts only, so called adenomyoma ${ }^{7}$. When the pancreaticobiliary type ducts predominate, they are often surrounded by hypertopic smooth muscle bundles.

It can be found anywhere in the gastrointestinal tract and the predilection site is the stomach, mostly in the antrum and prepyloric region on the greater curvature or posterior wall, duodenum, jejunum and Meckel diverticulum. Unusual localizations are the colon, spleen, liver, biliary tract, mesentery and lymph nodes. Also, heterotopic pancreas may be found immature teratomas, particularly of mediastinal origin ${ }^{3,4}$. Despite its congenital origin, a heterotopic pancreas clinically manifests itself in older adults. Most cases of heterotopic pancreas are asymptomatic, but non-specific gastrointestinal symptoms have been described in $30-40 \%$ of cases $^{8}$. If symptoms develop, they are most likely secondary to a mass effect. Large lesions may cause obstruction, ulceration, hemorrhage, or intussusception. Most patients complain of epigastric pain, nausea, vomiting and gastrointestinal bleeding. Complications are similar to those that occur in the pancreas itself and include acute pancreatitis, pancreatic cancer, insulinomas, gastrinomas and cystic degeneration ${ }^{9}$. The preoperative diagnosis of a heterotopic pancreas is still difficult regardless of the recent advance in diagnostic tools and techniques. There is no specific indicator or biochemical marker to diagnose a heterotopic pancreas. Preoperative diagnostic studies include upper gastrointestinal series, gastroduodenoscopy, computerized tomography and endoscopic ultrasound. Gastroduodenoscopy is an indispensable tool for the investigation of patients with upper gastrointestinal symptoms. However, it is generally difficult to produce an accurate endoscopic diagnosis of submucosal tumors such as heterotopic pancreas because biopsy specimens often fail to include the tumor tissue beneath the normal mucosa. Despite its characteristic features such as central umbilication in the tumor, this condition is difficult to diagnose endoscopically, because in tumors of less than $1.5 \mathrm{~cm}$ that umbilication is often absent. Endoscopic ultrasound is helpful for detecting small submucosal tumors $(<2 \mathrm{~cm})$, but it is not specific and cannot exclude other pathologies, such as carcinoid, fibroma, eosinophilic granuloma or leiomyoma ${ }^{5}$. A heterotopic pancreas typically presents in the upper gastrointestinal series as a welldelineated submucosal filling defect with a characteristic central indentation ${ }^{3,4}$. The CT appearance of most heterotopic pancreas enhance brightly, similar to an orthotopic pancreas. Reduced enhancement may be seen with inflammation of a heterotopic pancreas ${ }^{6}$.

Surgical exploration is required for a definitive diagnosis and to exclude neoplastic lesion for symptomatic patients ${ }^{2}$. When the lesion appears benign, local excision with frozen section is the treatment of choice ${ }^{2}$. However, in cases of malignancy or when the diagnosis is uncertain, more formal resection is mandatory. Similarly, in cases of heterotopic pancreas found incidentally, it is advisable to resect intraoperatively to avoid late complications and a second operation. In cases 
of a definitive and certain diagnosis, asymtomatic patients should remain under observation since the risk of malignant changes is no greater in heterotopic pancreas than in the pancreas itself $2,3,5$.

\section{References:}

1. Tanaka K, Tsunoda T, Eto T, et al. Diagnosisand management of heterotopic pancreas. Int Surg 1993; 78: 32-5.

2. Lai Edward CS, Tompkins RK. Heterotropic pancreas. Review of 26 year experience. Am J Surg 1988; 151: 697-700.

3. Barbosa JC, Dockerty M, Waugh JM. Pancreaticheterotopia: review of the literature and report of 41 authenticated surgical cases of which 25 were clinically significant. Surg Gynecol Obstet 1946; 82: 527-42.
4. Dolan RV, ReMine WH, Dockerty MB. The fate of heterotopic pancreatic tissue: a study of 212 cases. Arch Surg 1974; 109: 762-5.

6. Armstrong CP, King PM, Dixon JM, Macleod IB. The clinical significance of heterotopic pancreas in the gastrointestinal tract. Br J Surg 1981; 68: 384-7.

7. Heinrich H. Ein Beitrag zur Histologie des sogen. Akzessorischen Pankreas. Virchows Arch Pathol Anat 1909; 198: 392-401.

8. Monig SP, Sezner M, Raab M, Doz P, Eidt S. Heterotopic pancreas: a difficult diagnosis. Dig Dis Sci 1996; 41: 1238-40.

9. Qizilbash AH. Acute pancreatitis occurring in heterotopic pancreatic tissue in the gallbladder. Can J Surg 1976; 19: 414-23. 